\title{
Scheuermann's Kyphosis
}

\author{
Scheuermann Kifozu
}

Baris Ozoner ${ }^{1}$

Mehmet Cetinkaya ${ }^{2}$

Rakesh Dhokia ${ }^{2}$

${ }^{1}$ Erzincan Binali Yildirim University, Department of Neurosurgery, Erzincan, Turkey

${ }^{2}$ Royal Victoria Hospital, Spine Department of Orthopaedics \& Traumatology, Belfast, U.K

Gelis Tarihi/Received: 21 November 2018 Kabul Tarihi/Accepted: 24 December 2018

Address correspondence to: Mehmet Cetinkaya, Royal Victoria Hospital, Spine Department of Orthopaedics \& Traumatology, Belfast, U.K.

e-mail:gujcekic@gmail.com

ORCID

Mehmet Cetinkaya

https://orcid.org/0000-0002-7131-4280

\section{INTRODUCTION}

Scheuermann's disease is the most prevalent cause of hyperkyphosis in the adolescent thoracic spine. It is the second common disease that causes spinal deformity after idiopathic scoliosis (1-3). In this disease, narrow angled kyphotic angulation of the spine, vertebral corpus wedging, vertebral end plate irregularity, Schmorl's nodule, intervertebral disc disorders and disc space narrowing are observed (3-7). Although the disease begins to develop before puberty, it becomes evident in the adolescent period in growth spurt (8).

The initial definitions focused on the thoracic kyphosis variant of the disease $(9,10)$. It was later revealed that thoracolumbar or lumbar variants of the disease were also present $(1,3,11)$. The deformity is progressive and can become symptomatic in the period of rapid growth $(4,8)$. In symptomatic state, deformity can be accompanied by pain $(1,12)$. Minimal scoliosis may be combined with kyphotic deformity. However, this situation usually does not alter the treatment approach $(5,13,14)$. Classical radiological features includes irregular vertebral endplates, kyphosis more than 45 degrees with 5 degrees of wedging in 3 or more vertebrae $(3-5,7,14,15)$.

\section{History}

The disease was first described by Scheuermann in 1920 (9). In this definition, the correlation between thoracic vertebral corpus changes and clinical juvenile kyphosis is shown on radiography. Scheuermann 
emphasized that the wedging on the anterior part of the vertebral corpus caused spinal deformity. The definition made by Sorenson in 1964 yielded that anterior wedging of 5 degrees or higher in three adjacent vertebrae to be included in the diagnostic criteria of Scheuermann's kyphosis (10).

\section{Classification}

Scheuermann's disease predictably follows two patterns based on the apex of the deformity: Thoracic and thoracolumbar $(1,3)$. Thoracic pattern is widespread and incorporated with lumbar and cervical hyperlordosis (16). This situation is mostly seen in adolescents. The thoracolumbar or lumbar pattern is less frequent $(1,3,11)$. It is seen in adults who are involved in heavy sports activities and load lifting (11). In this disease, which occurs with localized pain and vertebral irregularities in the thoracolumbar junction, clinically significant kyphosis is not apparent as in the thoracic pattern $(1,11)$.

\section{Histology}

Electron microscopy reveals that the collagen fibers are weakened or vanished at the cartilaginous end plates of the vertebral corpus (17). This deterioration leads to the deformation of the vertebral bodies by loss of the growth zone $(17,18)$. Significant irregularity occurs at vertebral end plates. The continuity of the end plates is disrupted by protrusion of the disc material into the corpus (19).

\section{Epidemiology}

Current studies show the prevalence between $2.8 \%$ and $8 \%(20,21)$. This was demonstrated in a study on twins as $2.8 \%$ in 34,000 people (20). And $8 \%$ in another study conducted on radiological examinations with 10.000 individuals over 50 years old (21). There is a predisposition to males with Scheuermann's disease and this is seen in the study of 34,000 twins as $2: 1(20)$.

\section{Etiology}

The studies on the last decades have focused on the relevance of the disease to the genetic transition. In a Danish-based study of 35,000 twins born over a 50 -year period, $2.8 \%$ of the participants had Scheuermann's disease, and the heritability (familial genetic transition) was found to be $74 \%$ (22). In the same study, when monozygotic twins $(31 \%)$ and dizygotic twins $(19 \%)$ were evaluated in terms of concordance of the disease, it was found that concordance was significantly higher in monozygotic twins. In another genetic study, the autosomal dominant genetic inheritance of the disease and its association with three genes (Duffy,
COL1A1, COL1A2) were investigated (23). In that study, it was found that there was not any linkage with Scheuermann's disease. A mutation in COL2A1 was discovered to be interrelated with spondyloepiphyseal dysplasia similar to Scheuermann's kyphosis in serious osteoarthritis (24). The COL9A3 gene has been shown to be associated with radiographic Scheuermann's disease signs in patients with low back pain (25).

The other factor focused on is mechanical stress. Studies in this scope concentrate on the opinion that repetitive and non-daily intense loads cause deformation on the spine, resulting to Scheuermann's disease findings. This thesis is supported by Scheuermann, who first described the disease. The prevalence of the disease has been shown to increase in the workers who started to do heavy work at an early age (7). Studies in those participating in heavy sports activities also support this theory. In a study which 120 elite skiing athletes under the age of 17 were compared with their non-sporting peers demonstrated that end plate irregularities and Schmorl nodules were significantly higher in the athletes group (26). Also in a study conducted on Elite gymnasts, it was found that disc abnormalities, end plate irregularities and Schmorl nodes were more common than control group (27). Eventually, it has been shown that repetitive strain on the rats' tails for 2 hours per day for 2 months leads to histological changes similar to Scheuermann's disease (28). In another study conducted with twin sisters presents radiological findings of lumbar Scheuermann's disease were more prominent in who participated in heavy sports activities. Those patients were also complaining of pain (29). This study supports the theory that disease has the genetic basis and becomes evident by mechanical factors.

There are studies showing that increased body mass index is associated with Scheuermann kyphosis. Two studies with the control group found that patients with Scheuermann's disease had higher body mass index than the control group $(30,31)$. In the crosssectional case-control study of 10,000 students, the patients diagnosed with Scheuermann disease were found to be significantly higher in terms of height, weight, and body mass index than the control group. However, there was no correlation between weight, height, body mass index, and severity of deformity (31). In the study which 92 Scheuermann's kyphosis cases was matched with the control group, kyphosis group showed a significant increased body mass 
index. In the same study, contrary to the other one, the body mass index and maximum kyphosis angle were correlated with each other (30). In this study, it was emphasized that increased body mass index made the diagnosis difficult and the deformity increased due to delayed diagnosis.

\section{Clinical Presentations}

The most common complaint in Scheuermann's disease is deformity of the spine (13). There is a typical appearance in patients with thoracic Scheuermann's disease. The head is positioned ahead. Cervical and lumbar hyperlordosis develops to compensate for increased thoracic kyphosis. Similarly, the shoulders are positioned forward (Figure 1A). The kyphosis is fixed and becomes prominent by hyperflexion of the spine. When the patient is tilted forward, sharply angulated deformity is observed when viewed from the lateral side (Adams' Test-Figure 1B).

In the case of pain, this complaint is usually localized to the area of the deformity. Pain increases with physical activity and ameliorates with rest $(1,8)$. In a 32-year follow-up study comparing the normal population with individuals with Scheuermann kyphosis, it was concluded that pain was more experienced in the patient group. However, there was no difference in the effect of pain on daily living activities. Also, there was a significant difference in

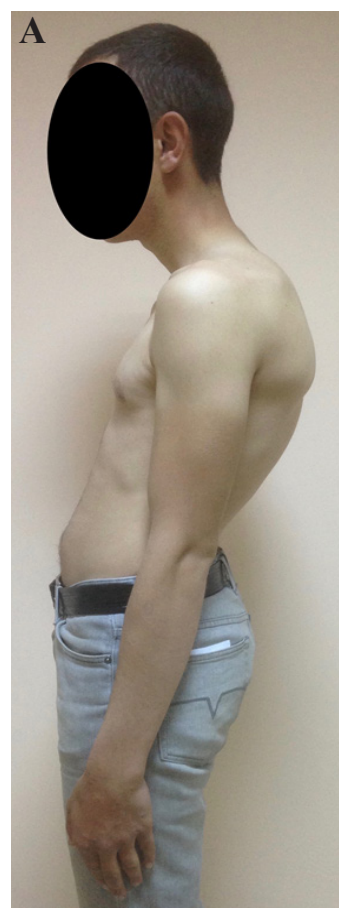

Figure 1A. The laterally sight of the patient showing the posterior sagittal balance, obvious kyphotic deformity, lumbar hyperlordosis, and the stooped shoulder position

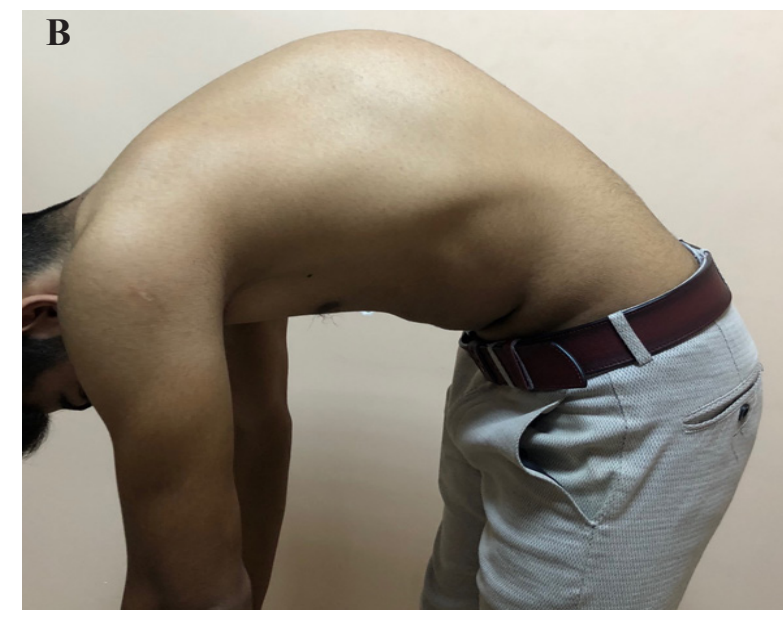

Figure 1B. Adam's forward bending test showing the steep thoracic kyphotic deformity $f$ the patient.

localization of pain. In the patient group, pain was more common in the deformity region. In the same study, the patient population had less leg pain than the normal population (8). If the pain is localized to the lumbar region and the patients should be investigated

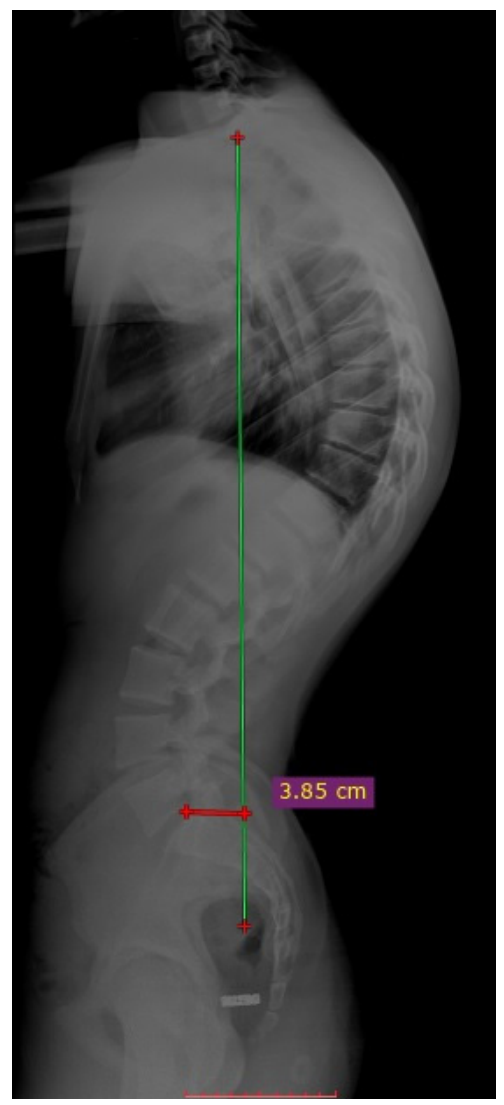

Figure 2. Lateral xray showing the posteriorly shifted sagittal balance of the patient. 


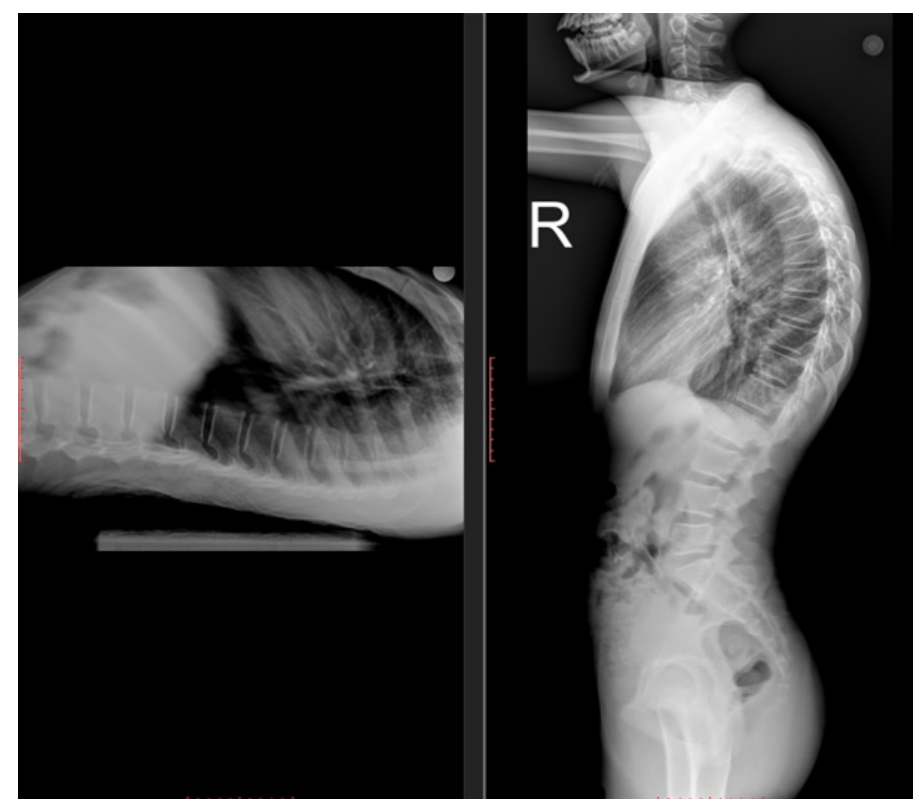

Figure 3. A: Lateral fulcrum radiograph showing the correction of the sagittal deformity. B: Lateral xray of the same patient showing the round back deformity.

in terms of spondylolysis. Increased lumbar lordosis may increase the strain on the pars interarticularis and cause fatigue fractures (32).

Neurological complications are extremely rare in Scheuermann's disease. It has been described that this condition is caused by compression of cord in the apex of the kyphosis in severe cases and thoracic herniated disc or extradural spinal cysts in this region (33-35).In cases with severe kyphosis, a decrease in lung capacity may occur due to compression on the chest. It has been shown that restrictive lung disease develops in cases with kyphotic angulation of more

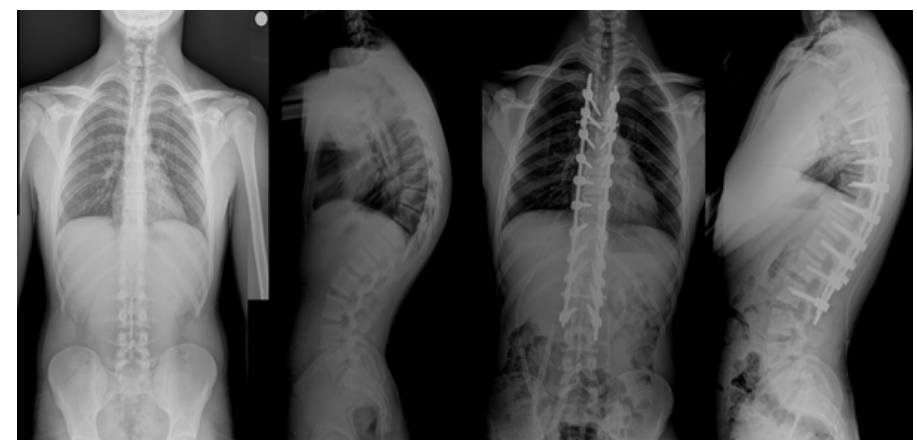

Figure 4. Preoperative and early postoperative anteroposterior and lateral X-rays of a patient with Scheuermann's kyphosis who underwent posterior correction and instrumentation of the deformity.

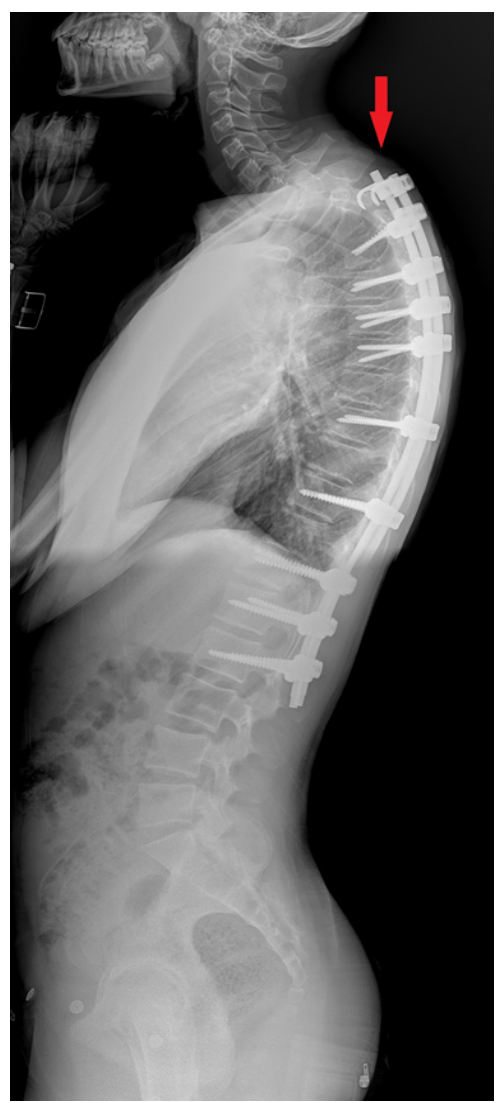

Figure 5. The lateral xray of a patient with Scheuermann's kyphosis who developed proximal junctional kyphosis after the posterior correction and instrumentation of the deformity.

than 100 degrees and where the kyphotic apex is between the first and eighth thoracic vertebrae. In the same study, in cases below 100 degrees, normal or above-normal lung capacities were observed (8).

\section{Radiological Findings}

The Spinal Deformity Study Group defines the thoracic kyphosis from the superior end plate of T2 to the inferior endplate of T12 utilizing the Cobb Method $(36,37)$. The accepted normal range of kyphosis is 10 to 40 degrees (36). However, Fon et al. described that the upper limit was higher and justified that limit was 45 degrees on a study of 316 normal subjects (38). As described, Scheuermann Kyphosis is diagnosed by lateral radiograph of entire spine. The lateral spinal images should be taken in clavicular position (Standing position with both arms are holding the contralateral clavicle) (39). As previously described, radiological diagnosis is accomplished with presence of kyphosis over 45 degrees, wedging of three or more vertebras by 5 degrees, existance of irregular 
end plates with Schmorl nodules and narrowing of disc spaces.

Patients with Scheuermann's disease commonly have negative sagittal balance. Normally, a line drawn down from the corpus of $\mathrm{C} 7$ vertebrae, called $\mathrm{C} 7$ plumb line, passes $2 \mathrm{~cm}$ in front of the sacral promontory. In patients with Scheuermann's disease, this line passes behind the promontorium (40) (Figure 2). The pelvic incidence is lower in Scheuermann's disease than the normal population (41). This is a direct result of pelvic retroversion to compensate for the negative sagittal balance. In Scheuermann's disease, the posibility of degeneration of the discs rises. MRI studies revealed that the Schmorl nodules, narrowed discs and the thoracic disc bulging increased significantly $(6,33)$. Furthermore, performing MRI can be discussed if surgery is required in Scheuermann's disease. A study conducted on 56 cases of Scheuermann's disease, the rate of spinal anomaly was found to be around $30 \%$. In the same study, although the MRI examination minimally reduced the possibility of neurological changes, it changed the operation plan in $4.7 \%$ of cases (42). So it can be recommended to regard performing MRI in operative Scheuermann's disease cases. Computed tomography imaging may help to better demonstrate changes in bone structure and may lead to earlier diagnosis.

\section{Differential Diagnosis}

Scheuermann's disease is mostly confused with postural kyphosis. Postural kyphosis can be differentiated from Scheuermann's disease by disperison of angulation to more vertebrae, lack of vertebral wedging, and loss of structural kyphosis on hyperextension or fulcrum lateral radiographs (4) (Figure 3). Adam's forward bending test is also effective in differential diagnosis. While narrow angulated kyphotic deformity is observed in Scheuermann kyphosis, a broader angled kyphosis appears in postural kyphosis.

\section{Treatment}

Determining the treatment method in Scheuermann's disease is based on the degree of the angular deformity, the age of the applicant and the associated symptoms (pain, neurological deficit). In adolescent cases with kyphosis less than 50 degrees, periodic radiological examinations should be performed for the evaluation of progression (43). In the absence of associated symptoms and progression of angular deformity, this follow-up is appropriate until bone maturity is completed. Treatment should be initiated in cases with kyphotic angulation of 50 degrees or more and progression is detected during follow-ups. There is no particular method, and many treatment methods are advocated for different conditions.

\section{-Rehabilitation}

Postural exercise treatments in Scheuerman's disease are aimed at strengthening paraspinal muscles, and mechanically correcting kyphosis and hyperlordosis. In addition hamstring stretching and balance exercises can be done. However, the effect of the exercise on the correction of kyphosis in Scheuermann disease has never been demonstrated, but the pain reduction can be achieved by rehabilitation. In a study, the results of treatment with physiotherapy, manual therapy and osteopathy combination in 312 patients showed a decrease of $16 \%$ to $32 \%$ in pain scoring (44).

\section{-Bracing}

Bracing is a considered treatment method in kyphosis less than 75 degrees and uncompleted skeletal maturity. In a study conducted on 274 patients, it was shown that bracing was unsuccessful in patients with kyphosis more than 75 degrees and surgical intervention was required (13). During bracing, there is a possibility that the treatment fails and the kyphotic deformity is likely to progress. The same study suggested that surgical intervention should be performed if bracing failed and progression of kyphosis was observed with angulation more than 60 degrees (13). It is thought that the use of brace will not be beneficial in adults when the skeletal maturation is complete.

There are many braces available for Scheuermann's disease. The most popular one of these is the Jewett corset. This brace forms the thoracolumbar spine in extension with three-point pressure. Also it can be modified according to the thoracolumbar curves. It has been shown to be effective in correcting the wedging in kyphotic deformity with full-time use (22 hours per day) for 12-18 months followed by part time use (12 hours per day) $(13,45)$. However, it is very difficult to tolerate the use of brace for so long. It has been argued that the removal of brace during the sport activities for 2-4 hours a day increases the acceptability of brace without reducing its effectiveness (46).

\section{-Surgery}

In adolescents surgical treatment should be taken into consideration in cases of severe deformity ( $>75$ degrees) and when it cannot be controlled by brace treatment (Figure 4). In adults, it should be preferred if there is a marked cosmetic deformity and the pain 
cannot be controlled by conservative methods. In Scheuermann's disease the thoracolumbar spine is shortened in the anterior column. And the spinal cord has been adapted to this shortening. Correction of the kyphosis angle will also cause the anterior column to become elongated. This situation causes the risk of developing neurological damage due to prolongation of medulla spinalis. Therefore, cord tension should be avoided by providing reduction of posterior vertebral column with performing osteotomies in the apex of the deformity $(5,14,15)$. The first publications about the surgical treatment of the disease include surgical approaches with Harrington and Luque instrumentation systems. Using the Harrington instrumentation system by Bradford et al., deformity correction was achieved at the beginning, especially in advanced kyphotic angulations. In this system, deformity was tried to be corrected by posterior compression. However, this improvement was worsened in follow-up (47). Luque instrumentation systems provided segmental fixation reducing the nonunion rates and iteration rates of the deformity. Sublaminar wiring was required in this method, thus increasing the risk of neurological deficit (48).

Recent studies have focused on the comparison of anterior/posterior combined approach and posterior only approach. In a study by Hosman et al (49), no significant difference was found in the correction of the deformity when the combined approach was compared to the posterior only approach. In a comparative study by Lee et al (50), posterior intervention was found to be more beneficial. In the combined approach group, the hybrid instrumentation system was used while the posterior approach group was stabilized by pedicle screws with the Smith-Peterson osteotomy. Correction rate of the deformity was higher in the posterior approach group but no complication was observed in this group. In addition, complications were seen including junctional deformities (Figure 5), temporary paraplegia, and wound infections in the combined group. In the study conducted by Lonner et al (51), there was no difference in terms of correction. Hybrid instrumentation was used in the combined group and all-screw stabilization was performed in the posterior group. While there was no complication in the posterior group, complications such as neurogenic bladder, renal failure, pneumothorax, and pulmonary embolism were observed in the combined group. In a study by Johnston et al (52), hybrid instrumentation was used in the combined group and closing wedge laminar resection was performed in the posterior group. There was no difference in terms of correction of deformity. In a study by Geck et al (53), using only posterior approach with Ponte osteotomies was shown that the kyphotic deformity of 75 degrees was corrected to 38 degrees. While no neurological complication was observed in this study which conducted on 17 cases, one case each had junctional kyphosis and late infection.

\section{CONCLUSION}

Scheuermann's disease is endemic in the community and may occur in different clinical presentations. In most of the cases, the deformity is the main complaint, but sometimes pain can accompany this complaint. The disease is diagnosed by lateral radiographs of the spine, and the Adam's test may be helpful in the diagnosis. Although the etiology of the disease is still controversial, it can be argued that the main reason is due to increased mechanical stress on the genetic basis. The major factors affecting the choice of treatment are the state of the skeletal maturation of the spine, severity of the deformity and its association with pain. Although conventional treatment methods such as periodic radiographic follow-up, rehabilitation and bracing are adequate in most cases, surgical treatment may be necessary in severe deformity. In the choice of surgical method, posterior only approaches with the osteotomies has become more popular due to their better correction results and lower complication rates.

Conflict of interest: Authors declare that there is no conflict of interest between the authors of the article.

Financial conflict of interest: Authors declare that they did not receive any financial support in this study.

Address correspondence to: Mehmet Cetinkaya, Royal Victoria Hospital, Spine Department of Orthopaedics \& Traumatology, Belfast, U.K.

Postal Code: BT12 6BA

Phone: +90532 7969887 Fax: +903122129008

e-mail: gujcekic@gmail.com

\section{REFERENCES}

1. Bezalel T, Carmeli E, Been E, et al. Scheuermann's disease: Current diagnosis and treatment approach. J Back Musculoskelet Rehabil 2014;27:383-90.

2. Graat HC, van Rhijn LW, Schrander-Stumpel CTRM, et al. Classical scheuermann disease in male monozygotic twins: Further support for the genetic etiology hypothesis. Spine (Phila Pa 1976) 2002;27(22):485-7.

3. Lowe TG. Scheuermann's disease. Orthop Clin North Am 1999;30:475-85.

4. Tribus CB. Scheuermann's kyphosis in adolescents and adults: Diagnosis and management. J Am Acad Orthop Surg 
1998;6(1):36-43.

5. Ali RM, Green DW, Patel TC. Scheuermann's kyphosis. Curr Opin Pediatr 1999;11:70-5.

6. Gokce E, Beyhan M. Radiological imaging findings of Scheuermann disease. World J Radiol 2016;8(11):895.

7. Scheuermann HW. The classic: Kyphosis dorsalis juvenilis. Clin Orthop Relat Res 1977;(128):5-7.

8. Murray PM, Weinstein SL, Spratt KE. The natural history and long-term follow-up of Scheuermann kyphosis. J Bone Joint Surg - Ser A 1993;75(2):236-48.

9. Scheuermann HW. Kyfosis dorsalis juvenilis. Ugeskr laeger 1920;82:385-93.

10. Sorensen KH. Scheuermann's juvenile kyphosis: Clinical appearances, radiography, aetiology and prognosis. Copenhagen: Munksgaard; 1964.

11. Blumenthal SL, Roach J, Herring JA. Lumbar Scheuermann's: A clinical series and classification. Spine (Phila Pa 1976) 1987;12(9):929-32.

12. Donzelli S, Negrini S, Zaina F, et al. Back pain in adolescents with spinal deformities. Ann Phys Rehabil Med 2018;61:154.

13. Sachs B, Bradford D, Winter R, et al. Scheuermann kyphosis. Follow-up of Milwaukee-brace treatment. J Bone Joint Surg Ser A. 1987;69(1):50-7.

14. Tsirikos AI, Jain AK. Scheuermann's kyphosis; Current controversies. Bone Joint J 2011;93-B(7):857-64.

15. Tsirikos Al. Scheuermann's kyphosis: An update. J Surg Orthop Adv 2009;18(3):122-8.

16. Loder RT. The sagittal profile of the cervical and lumbosacral spine in Scheuermann thoracic kyphosis. J Spinal Disord 2001;14(3):226-31.

17. Aufdermaur M, Spycher M. Pathogenesis of osteochondrosis juvenilis Scheuermann. J Orthop Res 1986;4(4):452-7.

18. Aufdermaur M. Juvenile kyphosis (Scheuermann's disease): Radiography, histology, and pathogenesis. Clin Orthop Relat Res 1981;(154):166-74.

19. Bradford DS, Moe JH. Scheuermann's juvenile kyphosis. A histologic study. Clin Orthop Relat Res 1975;(110):45-53.

20. Damborg F, Engell V, Nielsen J, et al. Genetic epidemiology of scheuermann's disease: Heritability and prevalence over a 50-year period. Acta Orthop 2011;82(5):602-5.

21. Armbrecht G, Felsenberg D, Ganswindt M, et al. Vertebral scheuermann's disease in Europe: Prevalence, geographic variation and radiological correlates in men and women aged 50 and over. Osteoporos Int 2015;26(10):2509-19.

22. Damborg F, Engell V, Andersen M, et al. Prevalence, concordance, and heritability of scheuermann kyphosis based on a study of twins. J Bone Joint Surg - Ser A. 2006;88(10):2133-6.

23. Mckenzie L, Sillence D. Familial scheuermann disease: Agenetic and linkage study. I Med Genet 1992;29:41-5.

24. Löppönen T, Körkkö J, Lundan T, et al. Childhood-onset osteoarthritis, tall stature, and sensorineural hearing loss associated with arg 75-Cys mutation in procollagen type II gene (COL2A1). Arthritis Care Res 2004;51(6):925-32.

25. Karppinen J, Pääkkö $E$, Paassilta $P$, et al. Radiologic phenotypes in lumbar MR imaging for a gene defect in the COL9A3 gene of type IX collagen. Radiology 2003;227(1):143-8.

26. Rachbauer F, Sterzinger W, Eibl G. Radiographic abnormalities in the thoracolumbar spine of young elite skiers. Am J Sports Med 2001;29(4):446-9.

27. Swärd L, Hellström M, Jacobsson B, et al. Disc degeneration and associated abnormalities of the spine in elite gymnasts: A magnetic resonance imaging study. Spine (Phila Pa 1976) 1991;16(4):437-43

28. Revel M, Andre-Deshays C, Roudier R, et al. Effects of repetitive strains on vertebral end plates in young rats. Clin Orthop 1992;(279):303-9.

29. Van Linthoudt D, Revel M. Similar radiologic lesions of localized Scheuermann's disease of the lumbar spine in twin sisters Spine (Phila Pa 1976). 1994;19(8):987-9.

30. Lonner BS, Toombs CS, Husain QM, et al. Body mass index in adolescent spinal deformity: Comparison of Scheuermann's kyphosis, adolescent idiopathic scoliosis, and normal controls. Spine Deform 2015;3(4):318-26.

31. Fotiadis E, Kenanidis E, Samoladas E, et al. Scheuermann's disease: Focus on weight and height role. Eur Spine $\mathrm{J}$ 2008;17(5):673-8.

32. Ogilvie JW, Sherman J. Spondylolysis in Scheuermann's disease. Spine (Phila Pa 1976) 1987;12(3):251-3.

33. Chiu KY, Luk KD. Cord compression caused by multiple disc herniations and intraspinal cyst in Scheuermann's disease. Spine (Phila Pa 1976) 1995;20(9):1075-9.

34. Bradford DS, Garica A. Neurological complications in Scheuermann's disease. A case report and review of the literature. J Bone Joint Surg Am 1969;51(3):567-72.

35. Kapetanos GA, Hantzidis PT, Anagnostidis KS, et al. Thoracic cord compression caused by disk herniation in Scheuermann's disease: A case report and review of the literature. Eur Spine J 2006;15(5):553-8

36. Micheal OB, Timothy K, Kathy B, et al. Spinal deformity study group radiographic measurement manuel. Washington: Medtronic Sofamor Danek (Inc.) 2008:87.

37. Cobb JR. Outline for the study of scoliosis. Instr Course Lect 1948:5:261-75

38. Fon GJ, Pitt MJ, Thies AC. Thoracic kyphosis: Range in normal subjects. Am J Roentgenol 1980;134(5):979-83.

39. Winter RB, Lonstein JE, Denis F. Sagittal spinal alignment: The true measurement, norms, and description of correction for thoracic kyphosis. J Spinal Disord Tech 2009;22(5):311-4

40. Lowe TG, Kasten MD. An analysis of sagittal curves and balance after cotrel-dubousset instrumentation for kyphosis secondary to Scheuermann's disease: A review of 32 patients. Spine (Phila Pa 1976) 1994;19(15):1680-5.

41. Jiang L, Qiu Y, Xu L, et al. Sagittal spinopelvic alignment in adolescents associated with Scheuermann's kyphosis: A comparison with normal population. Eur Spine J 2014;23(7):1420-6.

42. Lonner BS, Toombs CS, Mechlin M, et al. MRI screening in operative Scheuermann kyphosis: Is it necessary? Spine Deform 2017;5(2):124-33.

43. Platero D, Luna JD, Pedraza V. Juvenile kyphosis: Effects of different variables on conservative treatment outcome. Acta Orthop Belg 1997;63(3):194-201.

44. Weiß HR, Ddeckmann J, Gerner HJ. Effect of intensive rehabilitation on pain in patients with Scheuermann's disease. Stud Health Technol Inform 2002;88:254-7.

45. Montgomery SP, Erwin WE. Scheuermann's kyphosis - Longterm results of Milwaukee brace treatment. Spine (Phila Pa 1976) 1981;6(1):5-8.

46. Vedantam R, Lenke LG, Keeney JA, et al. Comparison of standing sagittal spinalalignmentinasymptomaticadolescents and adults. Spine (Phila Pa 1976) 1998;23(2):211-5.

47. Bradford DS, Moe JH, Montalvo FJ, et al. Scheuermann's 
kyphosis. Results of surgical treatment by posterior spine arthrodesis in twenty two patients. J Bone Jt Surg - Ser A 1975;57(4):439-48.

48. Luque ER. Segmental spinal instrumentation of the lumbar spine. Clin Orthop Relat Res 1982;163:192-8.

49. Hosman AJ, Langeloo DD, De Kleuver M,et al. Analysis of the sagittal plane after surgical management for Scheuermann's disease: A view on overcorrection and the use of an anterior release. Spine (Phila Pa 1976) 2002;27(2):167-75.

50. Lee SS, Lenke LG, Kuklo TR, et al. Comparison of Scheuermann kyphosis correction by posterior-only thoracic pedicle screw fixation versus combined anterior/posterior fusion. Spine 2006;31:2316-21.
51. Lonner BS, Newton P, Betz R, et al. Operative management of Scheuermann's kyphosis in 78 patients: Radiographic outcomes, complications, and technique. Spine (Phila Pa 1976) 2007;32(24):2644-52.

52. Johnston CE, Elerson E, Dagher G. Correction of adolescent hyperkyphosis with posterior-only threaded rod compression instrumentation: Is anterior spinal fusion still necessary? Spine 2005;30:1528-34.

53. Geck MJ, Macagno A, Ponte A, et al. The ponte procedure: Posterior only treatment of Scheuermann's kyphosis using segmental posterior shortening and pedicle screw instrumentation. J Spinal Disord Tech 2007;20(8):586-93. 